\title{
Los niños, niñas y jóvenes desvinculados de los grupos armados ilegales en Colombia: ¿Víctimas de la violencia política o sujetos del delito?*
}

\author{
Children and Adolescents Demobilized from Illegal Armed Groups \\ in Colombia: ¿Victims of Political Violence or Perpetrators of the Crime? \\ As crianças e jovens desvinculados dos grupos armados ilegais \\ na Colômbia: ¿Vítimas da violência política ou sujeitos do delito?
}

\author{
CAMILO BÁCARES JARA
}

FECHA DE RECEPCIÓN: 21 DE ENERO DE 2015. FECHA DE ACEPTACIÓN: 28 DE ABRIL DE 2015

Doi: dx.doi.org/10.12804/esj 17.02.2015.07

Para citar este artículo: Bácares Jara, C. (2015). Los niños, niñas y jóvenes de los grupos armados ilegales en Colombia: ¿Víctimas de la violencia política o sujetos del delito? Estudios Socio-Jurídicos, 17(2), 233-262. Doi: dx.doi.org/10.12804/ esj 17.02.2015.07

\section{RESUMEN}

El presente texto tiene como objetivo interrogar la definición que hacen las leyes 782 de 2002 y 1448 de 2011 de los niños, niñas y adolescentes víctimas de la violencia política, con el firme propósito de explicar y argumentar de dónde viene tal posición y por qué es urgente comprenderla y aplicarla. Para ello, recoge y recorre los elementos sociales, políticos y jurídicos que impulsaron el reconocimiento de las infancias excombatientes como víctimas de la guerra y genera una discusión a favor de esta mirada, en contraposición al reconocimiento que pueda hacerse de ellas bajo valoraciones retribucionistas, que las leen como victimarias e imputables de la ley penal.

Palabras clave: derechos del niño, conflicto armado, violencia política, niños y guerra.

* Artículo de revisión.

** Magíster en Política Social con Mención en Promoción de la Infancia Universidad Nacional Mayor de San Marcos, Perú. Docente del Departamento de Humanidades de la Universidad El Bosque, Bogotá, Colombia. Investigador independiente en temáticas, fenómenos y problemáticas referidas a las infancias. Correo electrónico: comalarulfo@hotmail.com 


\section{ABSTRACT}

This paper is concerned with questioning the definition that make the laws, 782, 2002 and 1448,2011 children and adolescents as victims of political violence with the firm purpose to explain and argue such a position where it comes from and why it is urgent to understand and apply. This, travels the social, political and legal factors that prompted the recognition of veterans childhoods as victims of war and generates an argument for this view as opposed recognition that may be made of them under retributivists valuations that read as victimizers and attributable to the criminal law.

Key words: Rights of the child armed conflict, children and war.

\section{RESUMO}

O presente texto interessa-se por interrogar a definição que fazem as leis, 782 de 2002 e 1448 de 2011, de crianças e adolescentes como vítimas da violência política com o firme propósito de explicar e argumentar de onde vem tal posição e porquê é urgente compreendê-la e aplica-la. Para isto, recolhe e recorre os elementos sociais, políticos e jurídicos que impulsaram o reconhecimento das infâncias ex-combatentes como vítimas da guerra e gera uma discussão a favor desta visão em contraposição do reconhecimento que possa fazer-se delas sob valorações retribucionistas que as leem como vitimarias e imputáveis da lei penal.

Palavras- chave: Dereitos da criança, Conflito armado, Violência Política, Crianças e Guerra.

"Lo más terrible de la guerra es la muerte, naturalmente, pero después de eso lo más terrible es que siempre nos quedará un rinconcito donde nos avergonzamos de haber sobrevivido [...] Sabemos bien que los que murieron en la guerra, especialmente en las guerras modernas, que son guerras contra la población civil, no merecian morir más que nosotros. $Y$, sin embargo, fueron ellos los que murieron y nosotros no, y eso, mirado desde suficiente altura, es una vergüenza". Tomás Segovia; Guerra, infancia y cotidianidad 


\section{Introducción}

La palabra víctima, de la raíz vinciere, significa haber experimentado dolor, daño o muerte por culpa ajena y acción de un tercero. Víctima es entonces quien ha sido atado a un sufrimiento (Íñiguez, 2003, p.15). En la sociedad colombiana, según estimaciones oficiales, a 2015 se calcula la existencia de 7.337 .667 personas que, en algún momento, fueron atadas a los procedimientos y violencias de los actores legales e ilegales del conflicto armado. ${ }^{1}$

A los niños, niñas y adolescentes (NNA) ${ }^{2}$ reclutados para ejercer los oficios de la guerra y asegurar la reproductibilidad de las tropas ilegales, también se les ha categorizado como víctimas de un abuso de poder adultocéntrico que los ha vinculado a un padecimiento. La Ley 1448 de 2011, la más reciente en la materia, lo deja claro al señalarlo taxativamente en su articulado. Pese a esto, la vivencia a fondo de esta categorización enfrenta variados peligros. Por un lado, la recurrencia de resistencias institucionales que la inhabilitan, entre las cuales, el uso de NNA excombatientes en los roles de guías continúa como un hecho vigente (Springer, 2012; Bácares, 2014; Holm, 2006; Pachón, 2009; Coalico, 2005, 2007; Defensoría del Pueblo, 2006). Por otro lado, los imaginarios sociales en torno a los NNA que consume y expulsa la guerra, de manera peligrosa, dan pistas contrarias y niegan la consideración de las infancias reclutadas como víctimas de la violencia política.

Al respecto, Acuña Vizcaya (2012) ha advertido que todavía son habituales en la reflexión jurídica una serie de argumentos intencionados para legitimar la responsabilidad penal de los menores de edad reclutados por las guerrillas y los grupos paramilitares. De un lado, la concepción biologicista sugiere que es válido sancionar a los adolescentes mayores de 14 años, así como otras consideraciones afirman que el reclutamiento es voluntario o que el NNA siempre tuvo la posibilidad de no hacer, "esto es, la capacidad de no tomar parte en los actos delictivos desarrollados por el grupo

1 Esta es la cifra de víctimas del conflicto armado a la fecha de la redacción de este texto. Para más información consultar la página de la Unidad para la Atención y Reparación integral a las Víctimas http://www.unidadvictimas.gov.co/index.php/en/

2 En adelante se utilizará esta sigla para referirse a los niños, niñas y adolescentes tanto en plural, como en singular. 
armado al margen de la ley, optando por retirarse, por volarse o desertar" (Acuña, 2012, p. 25).

Del mismo modo, el clima social y político develado por recientes investigaciones de opinión promueve que los exmiembros de las organizaciones al margen de la ley (donde caben los menores de edad) no sean beneficiarios de créditos jurídicos ni de privilegio político alguno (Lapop y Universidad de los Andes, 2013). Téngase en cuenta que 70\% de la población nacional concibe que aquel que cometió una infracción de sangre en la guerra debe ir a la cárcel (Comisión Nacional de Memoria Histórica 2012, p. 64), y en un dato no menor, el $48 \%$ considera que quienes se desmovilizan voluntariamente deberían tener el mismo destino (Comisión Nacional de Memoria Histórica, 2012, p. 61).

En ese sentido, el presente artículo analiza los componentes políticos, sociales e históricos que llevaron a que a los NNA desvinculados de los actores armados ilegales se les pronunciara como víctimas en las leyes 418 de 1997, 782 de 2002 y en 1448 de 2011, con el ánimo declarado de servir como argumento ante cualquier provocación retribucionista que pretenda minimizar y violar tal condición (El Espectador, 2014). En otras palabras, discute e interpreta la constitución sociohistórica de la caracterización del menor de edad desvinculado como víctima, dejando de lado la explicación reiterada y usual de un listado de instrumentos jurídicos que así lo avalan y ordenan (Organización Internacional para las Migraciones \& Procuraduría General de la Nación 2007; OIM, ICBF \& UNICEF, 2014).

El texto ofrece, en un primer lugar, algunos antecedentes que dan cuenta de los orígenes políticos y de la mediación internacional presente en la configuración de los NNA desvinculados como víctimas. En segundo lugar, presenta al enfoque psicosocial a modo de pilar decisivo en la reflexión que sostiene la victimización. En tercer lugar, señala la aparición del paradigma sociojurídico de la protección integral como un patrón que elevó a los NNA desvinculados al estatus de sujetos de derechos, con la prerrogativa incluida de la restitución ante los acontecimientos de la guerra. En cuarto lugar, explica las consecuencias que tiene para los NNA desvinculados, que el reclutamiento ilegal haya sido elevado a un delito penal. Finalmente, analiza y discute las razones por las cuales la insinuación de los NNA desvinculados a modo de exclusivos victimarios, pierden peso, frente a la configuración que los afirma como víctimas de la violencia política. 


\section{La legislación afirma al niño desvinculado como víctima, ¿por qué, cómo y cuándo?}

Toda guerra produce víctimas y victimarios. No obstante, son los hombres de armas quienes comúnmente concentran la atención de las instituciones en el terreno de la eliminación y en los esfuerzos políticos y jurídicos por reincorporarlos a la sociedad, al otorgarles un conjunto de posibilidades, a veces cortoplacistas y en otras ocasiones con un trazado generacional, a sus derechos en el retorno a la legalidad. En Colombia, la lista es larga en lo que refiere a la atención administrativa de organizaciones armadas ilegales, luego de que estas se decidieran por la desmovilización de sus hombres. Solamente en el siglo XX, según Cárdenas, Madrid y Rodríguez (2003), mal contados, se reconocen cinco períodos históricos en los que varios grupos armados al margen de la ley abandonaron las armas a cambio de amnistías, indultos, reformas locales, cupos políticos y un sistema de bonos socioeconómicos durante un tiempo determinado tras su renuncia al belicismo (Cárdenas, Madrid \& Rodríguez, 2003).

A modo de resumen, se tienen las políticas públicas de desarme implementadas por el general Gustavo Rojas Pinilla en 1953, que permitieron que 6.540 guerrilleros de los Llanos Orientales, Antioquia, Tolima, el Magdalena Medio y el Eje Cafetero desistieran de la vida irregular (Cárdenas Sarrias, 2005). De la misma manera, la política de reinserción que promovió Alberto Lleras Camargo en los primeros pasos del Frente Nacional, mediante el Decreto 2582 de 1958 que ofertó licencias judiciales para todos aquellos que hubieran cometido delitos antes del 15 de octubre del año en cuestión, con dos objetivos muy definidos: legitimar los crímenes ejecutados por el conservatismo, la policía chulavita y el gobierno militar (Palacios, 2003), así como despoblar los remanentes insurgentes que concurrieron al camino de la rebelión, tras hacerse notorio que muchas promesas no llegaron a buen puerto o que a muchos líderes y mandos medios se les había asesinado (Molano, 1993).

A inicios de los noventa, la tendencia estatal continuó con un conjunto de esfuerzos de índole administrativo y jurídico que permitieron el desarme y reintegración de una multitud de hombres provenientes de nueve organizaciones guerrilleras: 
M-19 (900 combatientes); Partido Revolucionario de los Trabajadores (PRT), (200); Ejército Popular de Liberación (EPL), (2.000); Movimiento Armado Quintín Lame (MAQL, (157); Comandos Ernesto Rojas -disidencia del EPL- (25); Corriente de Renovación Socialista - disidencia del ELN- (433); Milicias Metropolitanas de Medellín (650); Milicias Populares del Pueblo y para el Pueblo y Milicias Independientes de Valle de Aburrá (no se encontró cifra); Frente Francisco Garnica (150); Movimiento Independiente Revolucionario-Comandos Armados (MIR-COAR) (200). Esto da un total aproximado de 4.715 desmovilizados (Cárdenas Sarrias, 2005, p. 11).

Entrado el siglo XXI, durante 2003-2006 tuvo lugar el último gran proceso de desmovilización de tropas militares ilegales acaecido en el país. Las Autodefensas Unidas de Colombia (AUC) dejaron un total de 31.670 paramilitares bajo el foco de la atención del Estado, en conexión con un modelo de alternatividad penal emanado de la Ley 975 de 2005. En la misma, las víctimas de la guerra (por lo menos en términos de enunciación legal) aparecieron por primera vez en el imaginario público gracias al artículo 5 de dicha ley:

Para los efectos de la presente ley se entiende por víctima la persona que individual o colectivamente haya sufrido daños directos tales como lesiones transitorias o permanentes que ocasionen algún tipo de discapacidad física, psíquica y/o sensorial (visual y/o auditiva), sufrimiento emocional, pérdida financiera o menoscabo de sus derechos fundamentales. Los daños deberán ser consecuencia de acciones que hayan transgredido la legislación penal, realizadas por grupos armados organizados al margen de la ley (Ley 975 de 2005).

Este novedoso beneplácito significó, pese a los cuestionamientos de diversos sectores (Gallón 2006), un punto de partida y de inflexión en el terreno meramente formal y legalista. A partir de entonces, y en comparación con años anteriores, las personas inermes, ajenas y afectadas por las confrontaciones empezaron a cobrar notoriedad a los ojos de la institucionalidad con una serie de leyes, decretos y reformas en el administración pública, destinadas a garantizarles los tres principios modernos del Derecho Internacional de los Derechos Humanos: la verdad, la justicia y la reparación. 
En el nuevo panorama político un grupo poblacional empezó a sobresalir. Los NNA excombatientes fueron reconocidos, de una u otra forma, en la definición general sobre las víctimas que contiene el artículo 15 de la ley 418 de 1997, promulgada durante la administración de Ernesto Samper, con la intención de facilitar acercamientos, diálogos y suscripciones de acuerdos de paz con las guerrillas de la época:

Para los efectos de esta ley se entiende por víctimas, aquellas personas de la población civil que sufren perjuicios en su vida, grave deterioro en su integridad personal y/o bienes, por razón de actos que se susciten en el marco del conflicto armado interno, tales como atentados terroristas, combates, ataques y masacres entre otros (Ley 418 de 1997).

Más adelante con la aparición de la Ley 782 de 2002, se reconoció que tanto los NNA violentados por el reclutamiento ilícito como la inmensa población desplazada por las dinámicas guerreristas eran tácitamente víctimas de la violencia política:

Para los efectos de esta ley, se entiende por víctimas de la violencia política, aquellas personas de la población civil que sufran perjuicios en su vida, o grave deterioro en su integridad personal o en sus bienes, por razón de atentados terroristas, combates, secuestros, ataques y masacres en el marco del conflicto armado interno. Son víctimas los desplazados en los términos del artículo 1o. de la Ley 387 de 1997.

Así mismo, se entiende por víctima de la violencia política toda persona menor de edad que tome parte en las hostilidades (Ley 782 de 2002).

Esta posición política y legislativa, resultó unánime y refrendada a la luz de los paradigmas jurídicos con la expedición de la Ley 1448 de 2011, donde efectivamente los NNA desvinculados de los grupos armados al margen de la ley son reconocidos, por la institucionalidad, como víctimas de la guerra.

Ante este encadenamiento de leyes, ¿de dónde derivaron todos esos procesos?, ¿qué tipo de enunciados y postulados precedieron e impulsaron a estos actos legislativos? Ciertamente, en la escena internacional, los primeros documentos enfocados a reflexionar y visibilizar las dramáticas vivencias de los que en el exterior se tildaron como "child soldiers" es posible 
que solo aparecieran hasta mediados de 1994, con la publicación de dos informes que la Human Rights Watch le dedicó a la crisis manifiesta de esta problemática en Liberia y Sudán (Cifuentes, Aguirre E Lugo, 2011). En Colombia, aunque la Defensoría del Pueblo hacia finales de los noventa divulgó un conjunto de informes y boletines especiales en los que se anunciaba la gravedad y los efectos que el reclutamiento estaba causando en la infancia nacional $(1996,1997,1998)$, dicho tema careció de ecos sobresalientes e inmediatos en la academia y en los estudios de la violentología nacional. No obstante, se destacan los esfuerzos organizacionales e investigativos de la Coalición Contra la Vinculación de Niños, Niñas y Jóvenes al Conflicto Armado en Colombia (Coalico), la publicación de "Guerreros sin sombra: Niños, niñas y jóvenes vinculados al conflicto armado" (Álvarez E Aguirre, 2002) y las indagaciones periodísticas y testimoniales que empezaron con González (2002) y Lozano (2005).

Debido a la poca incidencia política e intelectual de la época sobre estos asuntos, las explicaciones acerca de la génesis que postula a los NNA como víctimas del conflicto armado en las leyes 418 de 1997, 782 de 2002 y 1448 de 2011 hay que buscarlas en otras coordenadas y las mismas son netamente exógenas, pues corresponden a los cuerpos normativos que dejó la utilización de los NNA en la II guerra mundial y que, del mismo modo, surgieron en respuesta a los largos procesos de liberación colonial de los sesenta y a las insurrecciones contra fácticas de los setenta y ochenta, que se beneficiaron de la mano de obra infantil para la guerra. De allí deviene la prohibición de reclutar menores de edad, con una parcialidad etaria delimitada a los quince años, establecida en el Protocolo II Adicional de los Convenios de Ginebra de 1949 (el Título II, artículo 4, numeral 3, literal C) o en el artículo 38 (numerales 2 y 3 ) de la Convención sobre los Derechos del Niño (CDN). Esta última como consecuencia de los esfuerzos e intereses del Reino Unido y de los Estados Unidos por mantener en sus tropas la presencia de adolescentes (O'Donnell, Año sin especificar, p. 5).

Justamente, desde la existencia de la CDN un hecho político definitivo concretó la suerte jurídica de los NNA reclutados in extenso en la historia contemporánea del conflicto armado en el país. La presión internacional para finiquitar, empoderar y darle otro rumbo a los 200.000 "child soldiers" que el informe de las Naciones Unidas, en cabeza de la señora Graça Machel 
(1996), halló y pronosticó en aproximadamente treinta y dos países del mundo en 1996, sumada a su visita al país ese mismo año, resultó crucial a nivel nacional para generar cambios de índole normativo.

Por ello, los albores de las leyes reivindicativas de los NNA como víctimas de la violencia política tienen una procedencia medianamente ubicable, más que surgir de preocupaciones nacionales autónomas, el cúmulo jurídico que desemboca en el postulado de la Ley 1448 de 2011, en relación a los NNA desvinculados de las guerrillas y los grupos paramilitares, tiene como basamento una cruzada internacional y foránea que arrancó en Naciones Unidas por cuenta de la interpretación de la CDN, la cual, de manera casi inmediata, rindió frutos a nivel nacional cuando la Corte Constitucional por medio de la Sentencia SU-200 en 1997 le ordenó a las Fuerzas Armadas la consideración de una edad mínima para el ejercicio de sus batidas y alistamientos.

Vale señalar que toda la ruta recorrida da luces de la simple emergencia de las tipificaciones jurídicas, creadas para controlar los ires y venires desafortunados de los NNA en los periplos bélicos gracias a la incidencia política mundial que comandó Graça Machel. Las razones sociológicas y psicológicas determinantes de la acepción novísima de víctima escapan a la presentación realizada, pues la ley nunca sobrepasa la función de definir

$y$, de la mano de un léxico, formular una realidad en espera de reinventar la administración pública en torno a una población o fenómeno. A todas estas, ¿cuáles son las ideas, paradigmas y pensamientos que subyacen a la afirmación que el ordenamiento colombiano hace de los NNA como víctimas de la guerra?

\section{La lectura psicosocial: el primer soporte de la victimización del NNA excombatiente}

La participación y el reclutamiento de los NNA en cada uno de los pasajes bélicos colombianos resultan a fondo una antípoda de lo inédito. Anteriormente, las voces críticas y la militancia para erradicar e impedir la inclusión de los NNA en cualquier tipo de ejército era algo totalmente inexistente. La impunidad (Jaramillo, 1989) de todas las guerras civiles del siglo XIX, el bandolerismo de los cincuenta, inclusive, gran parte del 
itinerario del conflicto armado contemporáneo, tienen larga data en dichos rubros cualitativos.

No obstante, en tiempos de recientes prohibiciones, una coyuntura local (cuando el informe de Machel ya había puesto de presente la urgencia de modificar este binomio de la niñez y la guerra) alteró la percepción nacional sobre los protagonistas de fondo que libran las conflagraciones (Human Rights Watch, 2003; Springer 2012): en el año 2000, el Ejército Nacional, en el desarrollo de la Operación Berlín en Suratá (Santander) develó, tras sendos combates con la columna Arturo Ruíz de las Fuerzas Armadas Revolucionarias de Colombia-Ejército del Pueblo (FARC-EP), la desbordante cifra de cien personas muertas - entre las que se encontraban tanto adultos como NNA- y setenta y dos menores de edad capturados (Londoño, 2003, p. 38). Semejante hecho tuvo un impacto decisivo para los NNA vinculados al conflicto, pues impulsó la Ley 782 de 2002 (artículo 17), que ordenó al Instituto Colombiano de Bienestar Familiar (ICBF) diseñar y ejecutar un programa de protección para la asistencia de todos los casos de menores de edad que hubieran tomado parte en las hostilidades.

En gran parte, ese señalamiento de tipo normativo "heredero a su vez de una larga cadena de disposiciones del Derecho Internacional Humanitario $(\mathrm{DIH})$ que en cierto modo ya elevaban a nivel mundial a los NNA a la categoría de víctimas, en razón de pertenecer a la población civil y a ser sujetos prevalentes de protección" (Organización Internacional para las Migraciones \& Procuraduría General de la Nación 2007), encontró asiento y se nutrió de una discusión y enfoque psicosocial que ya venía de tiempo atrás, y que casi paralelamente empezaba a exponer sus ideas (Ruiz Ceballos, 2001).

Adviértase que, las experiencias y posturas de la victimología vinculadas a los NNA contraventores de la ley penal fueron insumos claves para el despunte de la victimización, en lo que se refiere a la conjunción de los NNA y la guerra. A mediados de los noventa, esta corriente, prima hermana de la criminología, empezó a difundir la idea de que los NNA infractores, a pesar de quebrantar un Código Penal, eran a la vez víctimas de contextos sumidos en amplias y heterogéneas violencias generalizadas. Esta postura, en sí revolucionaria, propuso bifurcar la responsabilidad derivada del acto transgresor entre la institucionalidad que faltaba en su deber de ofertar alternativas de vida y el sujeto infanto-adolescente que infringía las nor- 
mas. En resumen, la medula del asunto pasaba por reconocer que en su mayoría los NNA marginales tienen una relación ineficaz con el Estado, que desemboca, comúnmente, en la titularidad de unos derechos de papel:

Aunque sea cierto todo, o casi todo, lo que se afirma acerca de la escalada de las infracciones juveniles, sin embargo conviene mirar paradójicamente, la otra cara de la Luna. Si observamos el problema desde la Victimología [...] vemos, con verdadero asombro que los menores y jóvenes padecen una victimación, mejor dicho, una macrovictimación, que con frecuencia se olvida.

Recientes investigaciones en centros docentes descubren que numerosos niños y niñas son a su vez víctimas de la delincuencia. Crecen en un ambiente adverso de violencia e inseguridad que lo invade todo en guetos del interior de las ciudades y en otras zonas marginadas que pueden resultar tan peligrosas como las zonas de guerra (Beristain, 1996, p. 183).

Por este motivo es que un autor como José Francisco Acuña, analizando los contextos de donde salen los NNA para la guerra, resalta una victimización fundada en lo que él denomina: "circunstancias de deficiencia de socialización" (Organización Internacional para las Migraciones \& Procuraduría General de la Nación, 2007, p. 22). Algo que no es más que la experiencia de vivir atrapado y bajo una cotidianidad ordenada por una autoridad ilegal que, ante la ausencia de una estatal, pone en jaque la vida y la integridad física por vía de los devenires propios de la guerra y de la ejecución del reclutamiento ilícito.

De otra parte, la desestructuración de la salud mental de los NNA que van renunciando a la servidumbre bélica también influyó sobremanera en la consolidación y el reconocimiento de los mismos como víctimas de la violencia política. Básicamente, se concluye que la cercanía a las acciones características y extremas de la milicia conllevan a los NNA portadores de las armas a experimentar efectos peores a los soportados por las víctimas de feroces maltratos intrafamiliares y escolares (Jiménez, 2013). En 2014, en la última investigación de gran impacto realizada con NNA desvinculados esto quedó nuevamente confirmado: $68,3 \%$ de ellos tiene distorsiones de pensamiento, 64,9\% sufren de episodios de depresión y ansiedad, 49,21\% tiene pensamientos de muerte y $61,9 \%$ tiene problemas de atención relacionados con episodios de miedo (OIM, ICBF \& UNICEF, 2014, p. 97). 
La guerra, en este sentido, aúpa traumas, denigra y anula cualquier pasaje de tranquilidad e indispone a quien la recorre (Díaz, 2002). La destrucción habitual de la salud mental que acarrean las hostilidades, autoriza y avala la concatenación de la categoría de víctima con toda la infancia desvinculada de los actores armados ilegales. A fin de cuentas, la exposición a lo bélico no trae más que puras y simples reverberaciones nocivas y lesivas; testimonios lo demuestran de sobra (Bácares, 2014, p. 127):

A veces me estorban por ahí cuando estoy durmiendo, mejor dicho. Llegan a mi cabeza y no me dejan dormir a veces. Yo cuando maté pues a la muchacha, ¿si me entiende? Pues como fue el primero, pues eso siempre el primero a uno le queda ahí. O sea, le mochaba la cabeza y ella volvía ¿si me entiende? Ella volvía y pues yo siempre volvía y la degollaba, muy feo, yo era muy asustado por eso. Ella nunca me reclamaba ni nada, sino que se quedaba mirándome y también veía mis, ¿cómo le dijera yo?... mis compañeros, mis compañeros al lado mío viendo. Por ejemplo, mataba uno ahorita y le hacían la necropsia, al otro día era el velorio, iba y me metía al velorio, iba al entierro y todo, como si nada. Entonces yo cada rato soñaba con eso que los veía a todos ahí, en la sala de, icómo se llama eso? En la sala de velación, yo siempre los veía a todos acumulados ahí, o sea, el uno acá, el otro acá, todos los muertos juntos. Yo siempre he tenido eso, yo siempre veo todos los muertos juntos a veces (...) (Hombre de 17 años, ex integrante de las AUC, en Bácares, 2014, p. 127).

\section{Ser víctima de la violencia política desde el paradigma de la protección integral}

Los pilares que sostienen la noción de víctima de la guerra que ampara a los NNA desvinculados se afianza no solo en la orientación psicosocial, sino en un paradigma que los postuló como sujetos de derechos. En efecto, las leyes 782 de 2002 y 1448 de 2011 devienen de ese modelo de pensamiento reivindicativo sobre la dignidad de la infancia que encuentra su expresión originaria en la aparición de la CDN. Colombia, al ratificarla por medio de la Ley 12 de 1991 e incorporarla al denominado bloque de constitucionalidad como matriz y fuente del derecho nacional, de las posteriores políticas públicas referidas a la niñez y la adolescencia, lo que 
hace, sin más, es seguir al dedillo los parámetros que trae a cuestas y que en el argot socio-jurídico se conocen y condensan en la doctrina de la protección integral.

Con base en lo anterior, se dio inicio a la deconstrucción de lo que tradicionalmente se había entendido como protección a los menores de edad, puesto que este nuevo paradigma:

Da evolución y vuelta de tuerca al concepto de protección que se manejaba en la Situación Irregular. Recuérdese que se institucionalizaba a los NNA con el afán de proteger sus cualidades y potencialidades para el futuro; obviamente como un discurso ficticio para encubrir el control social. En la perspectiva de la protección integral se piensa en actuar no solamente en la vulneración, en el daño, en la crisis, en la infracción sino complementariamente en las causas, los factores de riesgo y precipitantes de los distintos fenómenos que dañan a la infancia. De tal manera, la protección en la CDN se delimita en dos pisos de acción oficial. El primero, interesado en diagnosticar las causas estructurales y persistentes de la negación de los derechos de los NNA; protegiendo antes de las tragedias, si se puede decir así. Activando los derechos, para que no se queden en atributos inejecutables. En este caso la protección va hasta la naturaleza del hecho conocido como multiplicador de deficiencias y trampas a los derechos infanto-adolescentes permitiendo efectuar una acción coherente, a largo plazo y de fondo de parte de las instituciones encargadas de monitorearlos y velar por su respeto.

El segundo escalón, tiene en su base la disposición de actuar ante las contingencias impredecibles o en razón de la falta de prevención de fenómenos que pueden poner en jaque los derechos de tantas infancias, para rehabilitar o reparar la falencia vivida (Bácares, 2012, p. 90).

De este modo, en la propuesta holística de la CDN todo NNA, sin cabida a la discriminación, postergado de un cuidado y apoyo institucional en los entramados del conflicto armado, se entiende como víctima de unos derechos, que en el escenario público daban la impresión de estar vencidos. Aparece entonces el mea culpa de la institucionalidad que se la juega por implementar y darle la razón, tardíamente, a los derechos de los NNA, que vivieron el reclutamiento, aduciendo que, al tener lugar el delito, se pone en jaque la plataforma principal de sus desenvolvimientos, la vida y, 
muy al estilo de un castillo de naipes, las demás prerrogativas que les son transversales a un sujeto titular de derechos (ICBF, 2013).

Y es que, la mera existencia sistemática de NNA vinculados a las organizaciones armadas al margen de la ley, que según Unicef (2002) y Springer (2012) fluctúan entre los 2.000 y los 18.000 , habla muy mal de una prevención estatal, que en poco y nada ha logrado cauterizar la problemática del reclutamiento ilícito. De ahí que el organicismo nacional, con un amplio saldo de mora, postule a los NNA arrojados al rol del combatiente como sujetos asociados a un perjuicio que está lejos de ser episódico, puesto que la victimización de los NNA que caen en la actuación bélica se alimenta de momentos y experiencias pretéritas al instante de la vinculación.

Así lo soporta Springer (2012) cuando señala, que el 92\% de los NNA desvinculados que han pasado por el programa de restitución de derechos del ICBF, reportó que en sus escenarios civiles y familiares la inseguridad alimentaria era un hecho corriente y común, o aun peor, como lo recuerda Linares (2003), que el 99\% de ellos estén circunscritos a la estratificación 0,1 y 2 , que es de donde proviene la carne de cañón que consume el conflicto armado y donde predomina la marginalidad en todos los ámbitos del desarrollo humano.

Cabe subrayar que semejante apuesta de desagravio y resarcimiento de derechos, al tener como faro los principios de la protección integral, a su vez, es limitada en los designios que este paradigma le impone, para decirlo en otros términos, decepcionante y parcial en la comprensión de una administración pública, que debería atacar los factores de riesgo, principalmente, por el frente de la prevención. En el raciocinio nacional, en sintonía con la perdurabilidad de la guerra y los limitados esfuerzos por frenarla, los pasos y escalas de la protección integral no son sistémicos, sino desordenados, pues lo que es primero en su mandato se hace mal, y, lo que es lo segundo, termina siendo casi monopólico, en el cara a cara que se tiene con las problemáticas de los menores de edad que reclutan las guerrillas y el paramilitarismo.

Por consiguiente, sin mayores destellos, a los NNA excombatientes ser víctima de la violencia política no les sirve para nada más, por ahora, que para ser acreedores de unos contados créditos jurídicos y socioeconómicos de corta duración. La profundidad reformista, para la mala suerte de la infinidad de NNA en peligro de ser reclutados, llega hasta ahí. 


\section{Ser víctima de la violencia política a causa del delito del reclutamiento ilícito}

Los instrumentos del Derecho Internacional de los Derechos Humanos que sacan a la luz una definición estándar y tácita acerca de la victimización que genera la guerra en los NNA son escasos y contados (Rengifo, 2006). En el panorama histórico-jurídico, lo central son los postulados generales gravitantes alrededor del término víctima. Lo literal no señala a las infancias. Aun así, mediante una lectura a profundidad sí es dado avizorar los padecimientos actorales de los NNA en el conflicto armado, como una razón de sobra para reafirmar su inclusión en tan urgente y actual categoría. Efectivamente, así lo refleja el artículo 1 de la Declaración sobre los principios fundamentales de justicia para las víctimas de delitos y del abuso de poder, adoptado por la Asamblea General de las Naciones Unidas en 1985:

Se entenderá por "víctimas" las personas que, individual o colectivamente, hayan sufrido daños, inclusive lesiones físicas o mentales, sufrimiento emocional, pérdida financiera o menoscabo sustancial de los derechos fundamentales, como consecuencia de acciones $\mathrm{u}$ omisiones que violen la legislación penal vigente en los Estados Miembros, incluida la que proscribe el abuso de poder (Resolución 40/34/29).

De modo similar, el abordaje interpretativo que edificó la Sociedad Internacional de Victimología en la Declaración sobre justicia y asistencia para las víctimas apunta en la dirección de que aquella es quien sufre un perjuicio producto de una acción que:

a) Está en violación con las leyes penales

b) Es un crimen catalogado bajo la ley internacional

c) Constituye una violación a las normas de los Derechos Humanos internacionalmente reconocidos que protegen la vida, la libertad y la seguridad personal (...) (Organización de las Naciones Unidas, 1984).

$\mathrm{Al}$ respecto, a los NNA exparamilitares y exguerrilleros se les reconoce como víctimas, precisamente, por la ocurrencia de un delito penal que inhabilita sus derechos fundamentales. Sin la presencia de la infracción punible, esto es, del hecho denigrante y perjudicial de la titularidad de los derechos 
del menor de edad, tal binomio, a lo mejor, hubiera tenido pocas probabilidades de normalizarse en las leyes 782 de 2002 y en la 1448 de 2011.

En consecuencia, el tercer eje desencadenante de la noción de víctima de la violencia política surge de dos esfuerzos que elevaron el reclutamiento de los NNA a un acto ilícito. Por un lado, el artículo 14 de la Ley 418 de 1997, que más tarde sería especificado y refrendado en el artículo 162 del Código Penal Colombiano, en las siguientes palabras:

El que, con ocasión y en desarrollo de conflicto armado, reclute menores de dieciocho (18) años o los obligue a participar directa o indirectamente en las hostilidades o en acciones armadas, incurrirá en prisión de noventa y seis (96) a ciento ochenta (180) meses y multa de ochocientos (800) a mil quinientos (1500) salarios mínimos legales mensuales vigentes (Ley 599 de 2000).

En otra expresión, la aparición del Estatuto de Roma y de su artículo 8 (numeral b, literal XXVI) estipuló, tímidamente por cierto, en las responsabilidades penales individuales de los adultos que ofician ejércitos, la analogía del reclutamiento de NNA (de hasta quince años) como un crimen de guerra. Esta medida, que no es del todo garantista, pues deja en el aire a los menores de edad que rondan entre los 15 y 17 años, 11 meses y 30 días, sí ha resultado crucial a la hora del establecimiento de las primeras detenciones, juicios y condenas contra adultos que ejercieron o promocionaron, según Coalico (2009) el reclutamiento infanto-adolescente, fundamentalmente, en las guerras periféricas del África, tal como y lo ejemplifican los casos del expresidente de Liberia, Charles Taylor, condenado a purgar 50 años de prisión en La Haya, o de Thomas Lubanga Dyilo, excomandante de la Unión de Patriotas Congoleños, que tiene por delante una pena de 15 años de privación de la libertad por secuestrar, reclutar y entrenar a centenares de NNA con edades inferiores a los trece años.

Así pues, es permitido anotar que, detrás de la existencia de las infancias enroladas a los mandatos castrenses, se oculta una relación delictual que trasluce a dos personajes opuestos: por un lado, alguien que ejecuta, planea y permite la incorporación de los NNA a las funciones obligatorias de las hostilidades, y por otro, un sujeto pasivo de la infracción penal, a quien se le violan en lo sucesivo sus derechos fundamentales. Por lo anterior, 
la Corte Penal Internacional, en ocasión de la sentencia de confirmación de cargos del expediente de Thomas Lubanga Dyilo, consideró que el delito de reclutamiento es de carácter continuado, porque, se extienden y afloran otras violaciones a los Derechos Humanos, mientras los NNA sigan inscritos o militando en una organización al margen de la ley (Coalico, 2009).

\section{Los niños y niñas desvinculados de la guerra: ¿víctimas o victimarios?}

Históricamente a los NNA capturados o evadidos de la guerra se les ha criminalizado y medido con la misma vara retribucionista de los adultos. Dicho de otro modo, se les ha entendido y reducido en el derecho penal a simples delincuentes premeditados, conscientes y responsables de sus contravenciones a la ley penal. El caso peruano, verbigracia, así lo indica, pues tras consumarse el autogolpe de Estado fujimoriano del 5 de abril de 1992, en un afán por derrotar a cualquier costo a Sendero Luminoso y al Movimiento Revolucionario Túpac Amaru, se llevó a cabo una reforma jurídica que equiparaba en imputabilidad a los adolescentes sindicados de ser guerrilleros con sus jefes mayores de edad:

En apego al autoritarismo, la adolescencia fue altamente maltratada por la violencia estatal a partir de una concepción jurídica tutelarista que con la legislación antiterrorista surgida del Decreto Ley 25564 de 1992 hasta su derogación en 1995 con la Ley 26447, bajó la imputabilidad por delitos tipificados como terrorismo a adolescentes de 15 años de edad. De tal modo, durante tres años se obvió el artículo 37 de la Convención sobre los Derechos del Niño al mezclar en un mismo sistema penal a menores de edad con adultos. A ciencia cierta, cientos de jóvenes cayeron y fueron condenados en juicios sumarios ante jueces sin rostro en un claro fortalecimiento de la investigación policial, frente a un manifiesto debilitamiento de su derecho a la defensa (Bácares, 2011, p. 124).

Un poco más lejos, en África, la tendencia fue afín. El tratamiento y la comprensión jurídica que se le dio a los NNA señalados de participar en el genocidio ruandés de 1994, apuntó a sancionarlos a la par de los adultos: 
Después de la victoria del Frente Patriótico Ruandés (julio de 1994), la mayoría de los tutsis (y algunos hutus) apoyaron la iniciativa de crear tribunales para juzgar a los acusados de genocidio. Por otra parte, se aprobó una ley especial para rebajar la edad penal de 18 a 14 años. Así, cerca de 120.000 niños fueron encarcelados en Ruanda (Sedky-Lavandero, 1999, p. 37).

En Colombia, cerca de las postrimerías del siglo XX, la lectura correccionalista también echó raíces. Recuérdese que cuando todavía imperaba a sus anchas la doctrina de la situación irregular emanada del Código del Menor de 1989, en paralelo a la ratificación de la CDN, la esquizofrenia jurídica conjurada permitió que muchos jueces de la República condenaran a los NNA retenidos y huyentes del conflicto armado como infractores comunes de la ley penal con destino impajaritable hacia el Instituto El Redentor (Jiménez, 2013) o, bajo un lente paternalista como sujetos característicos de una situación de abandono y peligro moral (Linares, 2003, p. 64).

Mucho de lo sucedido, evidentemente, obedeció a la coexistencia de esos dos estadios jurídicos contradictorios, a saber, a la antítesis irresuelta de unos derechos recién reconocidos en la CDN, frente a un modelo, todavía vigente, que tenía una solución sencilla y habitual para todos sus problemas: el encierro, la institucionalización y el ocultamiento de la mirada pública de los NNA pobres e infractores. Sin embargo, un factor ideacional, probablemente una de las más viejas representaciones sociales sobre la infancia que se conocen, es decir, su categorización como peligrosa, también permitió que a los NNA desvinculados del conflicto armado se les criminalizara, castigara y encerrara (Pollock, 2004; Cussiánovich, 2004).

En lo que va corrido del siglo XXI, dicha mirada social ha vuelto emerger en el país, en atingencia a una demanda social que exige, que a los NNA asociados con cualquier modalidad delictiva, se les castigue con severidad y, de preferencia, con el encierro. Así lo prueba el proyecto de ley del 2010 que presentó la fallecida senadora Gilma Jiménez, encaminado a endurecer el tratamiento penal de los adolescentes entre los 14 y los 18 años (El Tiempo, 4 de septiembre de 2010), o la propuesta que realizó en el 2013, en la Sexta Cumbre de Alcaldes de Ciudades Capitales, el burgomaestre de Villavicencio, Juan Guillermo Zuluaga, sustentada en 
que a los adolescentes mayores de 15 años que participaran en delitos graves se les sancionara hasta con cuarenta años de prisión (El Tiempo, 5 de agosto de 2013).

En lo específico, sobre los NNA desvinculados de la guerra, la claridad y la argumentación que le hace frente a una cultura correccionalista y punitiva como la anteriormente descrita, a la fecha se limita a señalar, sin más, que la ley ordena que se les trate y reconozca como víctimas de la violencia política (Acuña, 2012, p. 27).

Esta afirmación, a todas luces verídica y necesaria, resulta insuficiente para resolver ciertas estigmatizaciones que rondan a la población menor de edad que dejó atrás el conflicto, a saber: la acusación patológica de los NNA excombatientes como violentos soberanos y su actuación en teoría impune en las lesiones y victimizaciones a civiles (Salcedo, 2012; AmadorBaquiro, 2010).

Sobre esto, la idea del reconocimiento de los NNA exguerrilleros y exparamilitares como víctimas de la violencia política ya ha ganado terreno, sin embargo, aparenta ser una empresa conducente al fracaso, pues como arguyen algunos, esta perspectiva favorece abiertamente una desresponsabilización del ejecutante de acciones delictivas en los momentos posteriores a la guerra:

Esta definición acentúa la dimensión del menor vinculado a los grupos armados ilegales como un sujeto jurídicamente inimputable. Ontológicamente parte de una concepción eminentemente determinista unicausal o multicausal y pone el énfasis explicativo en factores externos, como el Estado, la comunidad y la familia. La consecuencia identitaria fundamental es la des-responsabilización de los menores frente a sus acciones. Este efecto se deriva de confundir la categoría jurídica de imputabilidad con el concepto psicoeducativo de responsabilidad (Carmona, 2014, p. 167).

Como se lee, las críticas a las banderas jurídicas que definen a los NNA como víctimas sugieren que ellas amparan y promueven un déficit de responsabilidad en correspondencia a todo lo cometido en las hostilidades, al hacer hincapié, en su periplo por los ejércitos ilegales en factores externos y ajenos a la afirmación del yo. Empero, la validez de fondo de estos argumentos, se esfuma, si se tiene en cuenta, que las inscripciones de los NNA 
en los ciclos históricos del conflicto armado en el país, más que devenir instantáneas y cristalinamente soberanas, son el efecto de coerciones simbólicas (armas, uniformes, poder, dinero) puestas sobre el tapete por los actores armados ilegales, como también consecuencia de la aquiescencia de un Estado que nunca estuvo para prevenir el enganche a las reglas y cadenas de mando de la ilegalidad.

Indudablemente, no se puede ocultar que cerca de un 18\% de los NNA desvinculados, según sus confesiones a estudios institucionales, mataron en sus anteriores roles; que aproximadamente un 40\% disparó contra alguien, o que el 13\% participó en un secuestro (Vallés, 2003, p. 67). Pese a ello, suponer que esos actos anidaron en decisiones deliberadas, gratuitas y sádicas raya en una equivocación mayor. Precisamente, un sinnúmero de investigaciones cualitativas han evidenciado, con el tiempo, que el soporte mortífero de lo perpetrado por los NNA que sirvieron en una guerrilla o en un grupo paramilitar se funda en el contenido y la lógica de la orden inapelable: "o lo mata o lo mato"; "en el miedo a ser eliminado, en la imposición tanática y represiva de destruir a otra persona a cambio de seguir con vida" (Bácares, 2014, pp. 116-117):

Hay un refrán que dice: se cumple la orden o la milicia se acaba, entonces cuando uno no cumple la orden, por ejemplo, a mí me ordenan que lo mate a usted, entonces si yo no cumplo, entonces, bueno, paso al frente y dicen 'amarren a este 'hijueputa' que este no sirve para esto y matémoslo', y entonces lo matan a uno o ponen al mismo amigo, al mismo 'parcero' a matarlo a uno (Hombre de17 años ex integrante de las AUC, entrevista personal, 2007).

[...] le dieron la orden de que matara a un campesino y entonces el man se fue y no quiso matarlo, sino que se puso a quemar municiones y todo eso, para que pensaran que sí lo había matado. El campesino los sapiaba a los soldados. Entonces, se fue y el man dijo: 'no, yo ya lo maté'. Cuando el comandante mandó a otros dos a ver si sí era verdad y el campesino estaba vivo, entonces le dijeron que la munición y él no entregó nada, y la pistola la había botado, entonces el comandante lo sancionó: 'que iahora a prestar 8 horas de guardia en la noche!' y él no quiso. Entonces el comandante le dijo: 'usted, ¿qué es lo que quiere?', y él le dijo 'iah, yo quiero es como morirme, será!', y de una vez llamaron a consejo, de una dijeron quién quiere que éste man se muera y la mayoría votó 
porque él se muriera. Ahí mismo el comandante le metió el balazo aquí en la cabeza, y de una a una cañada (Hombre de 16 años, ex integrante del ELN, entrevista personal, 2007).

En otro orden de ideas, un debate común, en las aproximaciones a los NNA desembarcados del conflicto armado, es aquel que presume que en sus procesos de atención y protección lo sobresaliente es la impunidad. Evidentemente, los menores de edad exmiembros de la insurgencia y del paramilitarismo, tras su recorrido por la vía armada, quedan abiertos a que se les lea en unos roles que no dejan de ser contradictorios. En una orilla, emergen como damnificados del alistamiento ilícito, y en la otra, por las velocidades y operaciones implícitas en la labor del combatiente, como factibles victimarios de compañeros, contradictores militares y de la población civil (Bácares, 2014).

Inclusive, la propia Ley 782 de 2002, que se esfuerza en ratificar la concepción de la victimización, reproduce en una especie de confusión, la caracterización del NNA salido de la guerra como un criminal, dado que en el parágrafo 2 de su artículo 19 reconoce al menor de edad como sujeto del beneficio del indulto, y "por lo tanto, como victimario, en razón de que el indulto solamente puede ser otorgado a las personas que sean condenadas penalmente por la realización de un hecho punible" (Acuña, 2012, p. 26).

Por tal razón es importante responder, ¿la categorización del NNA desvinculado como víctima lo exime de hacerse cargo de crímenes de guerra y de lesa humanidad en los que pudiera haber participado?, ¿qué pasa con los derechos de las víctimas lesionadas por otras víctimas del conflicto armado? Preguntárselo, es pertinente, dado que todas las personas afectadas en el marco de la guerra, inclusive por menores de edad, tienen derecho al "esclarecimiento de la verdad material e histórica tanto sobre las causas, acciones y omisiones como de los efectos del crimen, llegar a determinar la responsabilidad penal de los culpables y la consecuente ejecución de una pena" (Castro Gutiérrez, 2006, p. 184).

Esencialmente, en ambos casos, la respuesta es negativa en atención a las regulaciones de los Derechos Humanos en todos los escenarios posibles. Que los NNA excombatientes, al reincorporarse a la legalidad, sean depositarios de un conjunto de beneficios jurídicos y socioeconómicos previstos en el Decreto 1385 de 1994, por el cual se creó el Comité Operativo para la Dejación de las Armas (CODA), encargado de oficializar esa 
certificación, de ningún modo logra ser compatible con cualquier suspicacia retribucionista acerca de la exención de una sanción en casos manifiestos de conculcación del DIH. Sobre esto, la Corte Constitucional, a través de la Sentencia C-203 de 2005, determinó que sí era exequible que a los menores de edad repatriados de la guerra se les procesara judicialmente, sin que ello fuera conducente a una estigmatización o a una puesta en jaque de sus derechos; así lo formuló el alto tribunal:

Los menores de edad que se desvinculan del conflicto armado sí pueden ser tratados jurídicamente, a pesar de su calidad de víctimas de la violencia política y del delito de reclutamiento forzado como infractores de la ley penal en razón de las conductas punibles en que hubieren incurrido con ocasión del conflicto, siempre y cuando se dé pleno cumplimiento, durante su investigación y juzgamiento, a las garantías mínimas constitucionales e internacionales (Sentencia C-203 de 2005).

Sucede que, el Principio de Oportunidad que cobija genéricamente a los NNA desvinculados (Bedoya, Guzmán \& Vanegas, 2010, p. 258), para nada es gratuito ni mucho menos automático. Explícitamente, como a continuación se verá, el artículo 175 de la Ley 1098 de 2006 enumera unas causales de consumación de la ilicitud, es decir, unas condiciones muy consecuentes con los factores permisivos de la vinculación de los NNA a la guerra (coacción, marginalidad, etc.), que de ser verificados en el examen judicial, autorizan la supresión de las conductas punibles acaecidas en el conflicto, a excepción, claro, de cualquier sindicación comprobada en un crimen de guerra o de lesa humanidad por parte de un NNA excombatiente (algo que en el fondo sigue siendo contradictorio, ya que como lo anota Acuña (2012, p. 58) el reclutamiento de menores de edad no se limita únicamente a convocar combatientes, también responde al uso y a las obligaciones que les imponen los grupos armados ilegales):

La Fiscalía General de la Nación podrá renunciar a la persecución penal, en los casos en que los adolescentes, en cualquier condición hayan hecho parte de grupos armados al margen de la ley, o hayan participado directa o indirectamente en las hostilidades o en acciones armadas o en los delitos cometidos por grupos armados al margen de la ley cuando: 
1. Se establezca que el adolescente tuvo como fundamento de su decisión las condiciones sociales, económicas y culturales de su medio para haber estimado como de mayor valor la pertenencia a un grupo armado al margen de la ley.

2. Se establezca que la situación de marginamiento social, económico y cultural no le permitían al adolescente contar con otras alternativas de desarrollo de su personalidad.

3. Se establezca que el adolescente no estaba en capacidad de orientar sus esfuerzos a conocer otra forma de participación social.

4. Por fuerza, amenaza, coacción y constreñimiento.

Los adolescentes que se desvinculen de grupos armados al margen de la ley, tendrán que ser remitidos al programa de atención especializada del Instituto Colombiano de Bienestar Familiar, para niños, niñas y adolescentes desvinculados de grupos armados irregulares.

Parágrafo. No se aplicará el principio de oportunidad cuando se trate de hechos que puedan significar violaciones graves al Derecho Internacional Humanitario, crímenes de lesa humanidad o genocidio de acuerdo con el Estatuto de Roma (Ley 1098 de 2006).

En síntesis, la categoría de víctima de la violencia política y los beneficios jurídico-económicos que acarrea la atención a la infancia desvinculada de los grupos armados ilegales, poco encaja con el auspicio a un menoscabo de los derechos de otras víctimas. Los filtros del Principio de Oportunidad están, precisamente, para evitar semejante descalabro. Aunque, concentrándonos en el punto neurálgico de toda esta discusión, lo crucial a tener en cuenta es el yerro gigantesco al que puede conllevar la interpretación unidimensional del NNA excombatiente como un victimario más resultante de las confrontaciones. Caer en la trampa de exigir condenas y tratamientos retribucionistas, similares a los de los adultos, para el conjunto de los NNA que despueblan las organizaciones armadas ilegales, es igual a abonar su criminalización consustancial, mejor dicho, suponer que cada NNA que nace en un contexto bélico, de rodillas al gobierno de un grupo insurgente o de una facción paramilitar, es un malhechor y homicida en potencia.

Además, buscar soluciones de tipo punitivo a problemas de envergadura social y política, recriminando a quienes aparecen como los más débiles y perjudicados de la cadena, da pie a la más desgastada de las estrategias 
y, de paso, a la reproductibilidad del fenómeno del reclutamiento ilícito: explicar y endilgar los fenómenos a costas de los personajes que los estelarizan; como quien dice, de las víctimas en pleno, para fortuna de los dos responsables expresos de toda esta tragedia humanitaria: el Estado por una comprobado aplazamiento de su deber constitucional de proteger a la infancia; en adición de las guerrillas y los bandos paramilitares, por causa de su premeditada política de reclutar ilegalmente a los NNA más marginados del país (Bácares, 2014).

\section{A modo de conclusiones}

Ante todo, la pronunciación de los NNA excombatientes de las insurgencias y de las facciones paramilitares como víctimas de la violencia política en la sucesión de leyes, 418 de 1997, 782 de 2002 y en la 1448 de 2011, hay que decirlo, es un acto hondamente meritorio. Y lo es, indiscutiblemente, por un sinfín de razones interdisciplinares y de distinta índole, que superan al mero argumento legal y a la propensión humanitaria subjetiva.

En primer término, tiene lugar de ser por una dilucidación histórica y holística de la violencia simbólica, y a veces física, que señala a los NNA como puerto, en una aparente decisión independiente, la incorporación al conflicto armado. Si bien es cierto, como lo muestran las estadísticas oficiales y las investigaciones de parto académico, que alrededor del 83\% de los muchachos procedentes de la guerra se vincularon a ella por decisión propia y deliberada (Vallés, 2003), es mucho más acertado leer que esas acciones individuales, en realidad fueron consecuentes con un gran contexto cultural, social, político y militar que al unísono las presionaba y legitimaba (Bácares, 2014).

Los ecos y efectos adquiridos y sufridos por el atravesamiento de la vida castrense ilegal, igualmente, alimentan la postulación del NNA evacuado de las hostilidades como víctima de la violencia política. Las perturbaciones en la salud mental que tiene que sobrellevar un muchacho, a quien en las directrices del combate se le entrena para matar a un semejante, son mayores. La guerra, en consecuencia, roba con esténtor cualquier asomo, sin intención de generalizar, de un mañana despejado de las cicatrices emanadas de los acontecimientos y obligaciones guerreristas, entre las 
que se pueden mencionar: "depresiones agudas, paranoias, crisis de ira, pensamientos suicidas, llantos repentinos, etc." (Springer, 2012, p. 48; OIM, ICBF \& UNICEF, 2014 p. 97).

Por otra parte, la elevación del reclutamiento de menores de edad al nivel de un delito y de un crimen de guerra, aunadas a las obligaciones jurídicas del Estado colombiano con los instrumentos internacionales de Derechos Humanos, marcaron a su vez la catalogación de los NNA reclutados por las guerrillas y las autodefensas como víctimas de las expresiones bélicas. El histórico hecho de que la CDN les reconociera derechos a las infancias en un punto de vista de larga duración y con el componente expreso de la restitución (artículo 39), dado el infortunio de que la institucionalidad prescindiera de sus obligaciones perentorias de garantizarle una vida digna a cada NNA habitante de una zona de guerra, fue una razón más de peso para afianzar el rumbo final de esa decisión legislativa.

En suma, los cimientos psicosociales, políticos y jurídicos que ponderan a los NNA reclutados ilícitamente como víctimas de la violencia política en la legislación nacional tienen fondo y son variados. Los resquicios posibles para que fructifiquen las intenciones y los argumentos retribucionistas contra esta población tienen, visto este panorama, mínimas oportunidades; adicionalmente, tal y como se sustentó en el último apartado de este ensayo, el principio de oportunidad que resguarda a las juventudes excombatientes es opuesto a la impunidad, pues se restringe, ante el más mínimo asomo de cualquier violación del DIH.

\section{Referencias}

Acuña, J. (2012). Tópica jurídica. En el caso de la judicialización de adolescentes desvinculados del conflicto armado, Bogotá: Universidad Nacional de Colombia.

Álvarez, G. \& Aguirre J. (2002). Guerreros sin sombra: niños, niñas y jóvenes vinculados al conflicto armado, Bogotá: Procuraduría General de la Nación.

Amador-Baquiro, J. (2010). El intersticio de la víctima-victimario: un análisis de los procesos de subjetivación de cuatro desvinculados de grupos armados en Colombia. Universitas Humanística. 69 (69): pp. 163-184. 
Asamblea General de las Naciones Unidas. Resolución 40/34/29 de 1985. Recuperada de http://www.unodc.org/pdf/compendium/compendium_2006_ es_part_03_02.pdf

Bácares, C. (2011). La desaparición forzada de los niños, niñas y adolescentes durante la violencia política en el Perú: una historia de desafiliaciones e impunidad. En R. Soto (Ed.) El Estado y el ejercicio ciudadano de la infancia en la sociedad peruana en los albores del siglo XXI (pp. 90-143). Huancayo: Universidad Nacional del Centro del Perú.

Bácares, C. (2012). Una aproximación hermenéutica a la Convención sobre los Derechos del Niño, Lima: Ifejant.

Bácares, C. (2014). Los pequeños ejércitos. Las representaciones sobre la vida y la muerte de los niños, niñas y jóvenes desvinculados de los grupos armados ilegales colombianos, Bogotá: Editorial Magisterio.

Bedoya, L., Guzmán, C. E Vanegas, C. (2010). Principio de Oportunidad. Bases conceptuales para su aplicación, Bogotá: Fiscalía General de la Nación.

Beristain, A. (1996). Menores infractores-víctimas ante las N.U. Cuaderno del Instituto Vasco de Criminología, 10, pp. 177-192.

Cárdenas Rivera, M., Madrid-Cárdenas, M. E Rodríguez, J. (2003). Bases para la construcción del posconflicto en Colombia. En Cárdenas, M. (Coord.), La construcción del posconflicto en Colombia. Enfoques desde la pluralidad, Bogotá: FESCOL, CEREC.

Cárdenas Sarrias, J. (2005). Los parias de la guerra: análisis del proceso de desmovilización individual, Bogotá: Ediciones Aurora.

Carmona, J. (2014). Definición de la situación de los menores desvinculados de los grupos armados ilegales en los actos jurídicos y sus efectos psicoeducativos. Estudios Sociojurídicos. 16 (2), pp. 163-177.

Castro, A. (2006). Algunas reflexiones sobre el contenido del derecho a la igualdad de las víctimas en el marco de la experiencia de justicia transicional en Colombia. Revista Derecho del Estado. 19 (dic), pp. 183-203.

Centro Nacional de Memoria Histórica. (2012). Encuesta nacional. ¿Qué piensan los colombianos después de siete años de justicia y paz?, Bogotá: CNMH.

Cifuentes, M., Aguirre, N. E Lugo, N. (2011). Niñas, niños y jóvenes excombatientes: revisión del tema. Revista Eleuthera, 5, pp. 93-124.

Coalico. (2005). Informe alterno al Comité de los Derechos del Niño. Recuperado del portal de la Coalición contra la vinculación de niños, niñas y jóvenes al conflicto armado en Colombia. Recuperado de http://coalico.org/archivo/InformeAlterno.pdf

Coalico. (2007). Informe Conflicto Armado en Colombia FRONTERAS: LA INFANCIA EN EL LIMITE. Recuperado de http://www.acnur.org/t3/uploads/pics/2206. pdf?view $=1$ 
Coalico. (2009). El delito invisible. Criterios para la investigación del delito de reclutamiento ilícito de niños y niñas en Colombia. Recuperado de http://coalico.org/ archivo/LDelitoinvisible.pdf

Colombia. Ley 1098 de 2006. Recuperado de http://www.secretariasenado.gov. co/senado/basedoc/ley_1098_2006.html

Colombia. Ley 12 de 1991. http://www.alcaldiabogota.gov.co/sisjur/normas/ Norma 1.jsp?i=10579

Colombia. Ley 1448 de 2011. http://www.alcaldiabogota.gov.co/sisjur/normas/ Norma 1.jsp?i=43043

Colombia. Ley 418 de 1997. http://www.alcaldiabogota.gov.co/sisjur/normas/ Norma 1.jsp?i $=6372$

Colombia. Ley 599 de 2000. Recuperada de http://www.secretariasenado.gov. co/senado/basedoc/ley_0599_2000.html

Colombia. Ley 782 de 2002. http://www.alcaldiabogota.gov.co/sisjur/normas/ Norma 1.jsp?i $=6677$

Colombia. Ley 975 de 2005. Recuperada de http://www.alcaldiabogota.gov.co/ sisjur/normas/Norma1.jsp?i=17161

Corte Constitucional de Colombia. Sentencia C-203/ 2005. Recuperada de http:// www.corteconstitucional.gov.co/relatoria/2005/c-203-05.htm

Corte Constitucional de Colombia. Sentencia SU-200/1997. Recuperada de http:// www.corteconstitucional.gov.co/relatoria/1997/SU200-97.htm

Cussiánovich, A. (2004). Aún yo no soy. En Aprodeh (Ed.) "Hasta sus menorcitos ahora lloran...". 1980-2000: Violencia contra niños, niñas y adolescentes. Selección de textos del Informe Final de la Comisión de la Verdad y la Reconciliación (pp. 11-25). Lima: Aprodeh.

Defensoría del Pueblo. (1996). La niñez y sus derechos: Víctimas de la violencia. El conflicto armado en Colombia y los menores de edad. Sistema de seguimiento y vigilancia (Boletín n. ${ }^{\circ}$ 2).

Defensoría del Pueblo. (1997). La niñez y sus Derechos: Menores de edad víctimas de violencia política (Boletín 3).

Defensoría del Pueblo. (1998). La niñez y sus Derechos: Niñas, niños y jóvenes en el conflicto armado (Boletín 4).

Defensoría del Pueblo-Unicef. (2006). Caracterización de las niñas, niños y adolescentes desvinculados de los grupos armados ilegales: inserción social y productiva desde un enfoque de Derechos Humanos. Recuperado de http://www.unicef.org/colombia/ pdf/co_resources_ID1_introduccion.pdf 
Díaz, C. (2002). Niños y niñas en el conflicto armado: ¿víctimas o actores? En Bello A. E Ruíz, S. (Eds), Conflicto armado, niñez y juventud: una perspectiva psicosocial, Bogotá: Universidad Nacional de Colombia.

Diez menores estarían implicados en los casos de las casas de pique. (30 de septiembre de 2014). El Espectador. Recuperado de http://www.elespectador.com/ noticias/bogota/mas-de-20-mil-jovenes-capturados-tres-anos-articulo-525337

Gallón, G. (2006). La CNRR: ¿Dr. Jekyll o Mr. Hyde? Por una comisión que contribuya a la efectiva reparación de los derechos de las víctimas de crímenes de guerra y de lesa humanidad en Colombia. Revista Pensamiento Jurídico, 17, pp. 265-311.

García Méndez, E. (2003). Consideraciones políticas para el manejo de los niños infractores en América Latina. En Tejeiro, C. (Coord), Niñez y conflicto armado: desde la desmovilización hacia la garantía integral de derechos de infancia, Bogotá: Universidad de los Andes.

Gobierno analizará endurecimiento de penas a menores. (5 de agosto de 2013). El Tiempo. Recuperado de http://www.eltiempo.com/archivo/documento/ CMS-12974494

González, G. (2002). Los niños de la guerra. Bogotá: Editorial Planeta.

Holm, C. (2006). Child Soldiers in Colombia, Stockholm: Stockholm University.

Human Rights Watch. (2003). Aprenderás a no llorar. Recuperado de http://www. unicef.org/colombia/conocimiento/aprenderas.htm

ICBF. (2013). Observar para proteger: Enfoques alternativos para valorar la dinámica y el riesgo de reclutamiento y utilización de niños, niñas y adolescentes por GAOML en Colombia. Recuperado de: http://www.icbf.gov.co:9005/observatorio/publico/ publicacion/43/guardar

Íniguez, P. (2003). La víctima: aspectos sustantivos y procesales (Tesis de Doctorado en Derecho, Universidad de Alicante, España).

Jaramillo, C. (1989). La guerra de los Mil Días, 1899-1902. En Tirado, A. (Ed), Nueva Historia de Colombia. Historia Política 1886-1946, Bogotá: Planeta.

Jiménez, A. (2013). Infancia. Ruptura y discontinuidades de su historia en Colombia, Bogotá: Ecoe Ediciones.

Lapop E Universidad de los Andes. (2013). ¿Qué piensan los colombianos del proceso de paz? Una mirada desde el Barómetro de las Américas. Recuperado de http:// www.obsdemocracia.org/fileman/files/INFORMES\%20COL/2013/Primera\%20Encuesta\%20Nacional\%20sobre\%20el\%20Proceso\%20de\%20Paz.pdf Linares, B. (2003). Jurisprudencia y política pública para la niñez desvinculada del conflicto armado. En Tejeiro, C. (Coord.). Niñez y conflicto armado: desde la 
desmovilización hacia la garantía integral de derechos de infancia, Bogotá: Universidad de los Andes.

Londoño, B. (2003). El Instituto Colombiano de Bienestar Familiar. Recuento histórico, desarrollos y planteamiento crítico. En Tejeiro, C. (Coord.). Niñez y conflicto armado: desde la desmovilización hacia la garantía integral de derechos de infancia. Bogotá: Universidad de los Andes.

Lozano, P. (2005). La guerra no es un juego de niños: historias de una infancia quebrada por el conflicto, Bogotá: Intermedio Editores.

Machel, G. (1996). El impacto de los conflictos armados sobre los niños. Informe de ONU pide medidas para proteger a los niños de los conflictos armados. Naciones Unidas, A/51/306.

Molano, A. (1993). Siguiendo el corte. Relatos de guerras y de tierras, Bogotá: El Ancora Editores.

O’Donell, D. (s.f.). La convención sobre los derechos del niño: estructura y contenido. En Derecho a tener Derecho. Derecho del niño. Políticas para la infancia. Tomo I. Caracas: Unicef.

OIM, ICBF \& UNICEF. (2014). Impacto del conflicto armado en el estado psicosocial de niños, niñas y adolescentes. Recuperado de http://www.oim.org.co/publicaciones-oim/ninez-desvinculada/3385-impacto-en-el-conflicto-armado-enel-estado-psicosocial-de-ninos-ninas-y-adolescentes.html

Organización de las Naciones Unidas. (1984). Informe de la reunión preparatoria interregional para el séptimo congreso de las naciones unidas sobre prevención del delito y tratamiento del delincuente. Recuperado de https://www.unodc.org/documents/ congress//Previous_Congresses/7th_Congress_1985/045_ACONF.121. IPM.4_Topic_III_-_Victims_of_Crime_Report_S.pdf

Organización Internacional para las Migraciones \& Procuraduría General de la Nación, (2007). ¿Judicialización de niños, niñas y adolescentes desvinculados del conflicto armado? Niños en la guerra: protegiendo y restituyendo sus derechos. Recuperado de http://www.oim.org.co/ninez-desvinculada/1423-judicializacion-de-ninosninas-y-adolescentes-desvinculados-del-conflicto-armado-ninos-en-la-guerraprotegiendo-y-restituyendo-sus-derechos.html

Pachón, X. (2009). La infancia perdida en Colombia: los menores en la guerra (Working Paper Series $N^{\circ}$. 15). Recuperado de: http://pdba.georgetown.edu/CLAS\%20 RESEARCH/Working\%20Papers/WP15.pdf. 2009.

Palacios, M. (2003). Entre la legitimidad y la violencia. Colombia 1875-1994, Bogotá: Editorial Norma.

Pollock, L. (2004). Los niños olvidados. Relaciones entre padres e hijos de 1500 a 1900, Ciudad de México: Fondo de Cultura Económica. 
Rengifo, J. (2006). El concepto de víctima en derecho internacional y su alcance en la ley de justicia y paz. Revista Pensamiento Jurídico, 17, pp. 103-115.

Ruiz, S. (2002). Impactos psicosociales de la participación de niñ@s y jóvenes en el conflicto armado. En Bello, A. \& Ruíz, S. (Eds.), Conflicto armado, niñez y juventud: una perspectiva psicosocial, Bogotá: Universidad Nacional de Colombia.

Salcedo, C. (2012). El problema de la impunidad en crímenes cometidos por niños soldados durante conflictos armados. Estudio de caso sobre Sierra Leona y Liberia. (Tesis de Pregrado en Ciencias Políticas y Relaciones Internacionales, Pontificia Universidad Javeriana, Colombia)

Se reabre debate en el país para que menores sean juzgados como adultos, (4 de septiembre de 2010). Recuperado de http://www.eltiempo.com/archivo/documento/CMS-7892689

Sedky-Lavandero, J. (1999). Ni un solo niño en la guerra: infancia y conflictos armados, Barcelona: Icaria Editorial.

Springer, N. (2012). Como corderos entre lobos. Del uso y reclutamiento de niñas, niños y adolescentes en el marco del conflicto armado y la criminalidad en Colombia. Recuperado de http://www.centrodememoriahistorica.gov.co/descargas/ informe_comoCorderosEntreLobos.pdf

Unicef (2012). La niñez colombiana en cifras. Recuperado de http://www.unicef. org/colombia/pdf/cifras.pdf

Vallés, J. (2003). Aspectos operativos y experiencias internacionales en desmovilización. En Tejeiro, C. (Coord). Niñez y conflicto armado: desde la desmovilización hacia la garantía integral de derechos de infancia, Bogotá: Universidad de los Andes. 